\title{
O que o Cliente de Bens Industriais Valoriza na Relação com os seus Fornecedores: o Caso de Empresas do Setor Metal Mecânico
}

\author{
Manuel Fernandes Silva Souza \\ Roberto Giro Moori \\ Reynaldo Cavalheiro Marcondes
}

\begin{abstract}
Resumo
Este artigo trata da identificação dos fatores-chave de retenção de clientes, no setor metal mecânico. A pesquisa que lhe deu suporte utilizou amostra não probabilística composta de 38 executivos de empresas associadas à ABIMAQ (Associação Brasileira da Indústria de Máquinas e Equipamentos). Para o tratamento dos dados foram aplicadas técnicas da estatística descritiva e da análise multivariada, tendo os resultados revelado que: os dez fatores-chaves de retenção podem ser resumidos em dois fatores principais, denominados “Fator Principal” e "Fator Secundário”; a "Qualidade dos Produtos” é o fator preponderante na retenção de clientes; mesmo alterando-se a técnica de tratamento dos dados, apenas a "Qualidade dos Produtos" evidenciou-se como o fator principal, enquanto os demais fatores-chaves não mantiveram suas posições; entre as empresas da amostra a ênfase principal é dada ao produto, muito mais que às questões de confiabilidade, velocidade e flexibilidade, mostrando não haver ainda visão ampla e integrada do processo do negócio. Por fim, este estudo mostrou não ser uma das tarefas mais fáceis identificar os fatores-chaves de retenção de clientes. Assim, este desafio persistirá, talvez, por longo tempo.
\end{abstract}

Palavras-chaves: retenção de clientes; qualidade; confiabilidade; velocidade; flexibilidade.

\begin{abstract}
This article deals with the identification of the key-factors of client retention in the metal mechanical sector. The research that gave support to it used a nonprobabilistic sample of companies associated to ABIMAQ (Brazilian Association of the Industry of Machines and Equipment) composed of 38 executives. For the data treatment were applied descriptive statistics and multivariate analysis techniques and the results revealed that the ten retention key-factors can be summarized into two factors called main and secondary factor. The quality of the products is preponderant factor to the client retention and when the data treatment technique was changed, quality of the products was proven as the main factor, while the other key-factors had not kept their position. The main emphasis to companies of the sample is given to the product much more than to the questions of reliability, speed and flexibility showing that companies do not still have an integrated vision of the business process. Finally, this study showed that to identify the client retention key-factors do not constitute one of the easiest tasks. Thus, this challenge will persist, maybe, for a long time.
\end{abstract}

Key words: clients retention; quality; reliability; speed; flexibility. 


\section{INTRODUÇÃO}

Tornou-se comum dizer que a sociedade atual é caótica. Certamente é um mundo menos estável e previsível do que no passado. Foster (1999) estudou 208 empresas durante 18 anos para identificar as que eram consistentemente bemsucedidas. Só três funcionaram durante os 18 anos. Metade não conseguiu manter o mesmo nível de atividade por mais de dois anos. Uma pesquisa recente de Ellen de Rooiji do Stratix Group, de Amsterdã, indicou que a expectativa de vida média de uma empresa de qualquer tamanho, no Japão e na maior parte da Europa, é de 12,5 anos. Na internet, o ciclo de vida das empresas é ainda menor. Só uma minúscula parte dos sites lançados em 1993 ainda existe.

Em um mundo assim, dinâmico e instável, pode-se pensar que há um conforto perverso em olhar as organizações como sujeitas às correntes do caos, em que as lideranças empresariais podem sentir-se liberadas da responsabilidade de planejar, comentam os consultores americanos Quinn Spitzer e Ron Evans (apud Cohen, 1999). Esse conforto perverso é uma das piores atitudes para uma organização. As revoluções de maior impacto para a humanidade acontecem, em um primeiro momento, sem que as pessoas se dêem conta de sua profundidade. Foi provavelmente assim com a descoberta do fogo, com a domesticação dos animais e com o início da estruturação da agricultura. Está sendo assim, novamente, com o que vários estudiosos denominam de revolução da informação, que tem a ver com o uso de computadores, a globalização e com a desregulamentação do mercado.

Hamel e Prahalad (1995) citam algumas grandes mudanças no ambiente corporativo, que passou de pouco competitivo a altamente competitivo; de local a global; as fronteiras industriais que eram claras, tornaram-se incertas; no lugar da estabilidade, entrou a volatilidade; em vez de intermediários, têm-se o acesso direto do fornecedor ao cliente; e a logística passou a ter papel fundamental no atendimento aos clientes.

Tudo isso pode ser muito ameaçador, mas também muito promissor. Com a globalização e a introdução de leis que desregulamentam os mercados, nada impede que uma empresa competidora invada o espaço que até então era considerado cativo de outra.

À medida que os mercados amadurecem e os custos de conquistar novos clientes aumentam, ênfase maior precisa ser dada à retenção dos clientes existentes e à estabilização dos negócios realizados com eles. A participação de mercado, que 
durante muito tempo foi a principal meta de muitas empresas, está sendo substituída pelo enfoque na participação do cliente, segundo Christopher (1999). Prossegue ainda o referido autor, argumentando que tem aumentado o interesse das empresas em saber qual a participação dos seus produtos e serviços nos gastos do cliente e qual a qualidade desta participação, de maneira a se mensurar o seu grau de fidelidade. Ainda que muitos fatores influenciem a qualidade e a duração de um relacionamento com o cliente, no geral melhor desempenho na prestação de serviços é fundamental para se reter o cliente (Christopher, 1999).

Produtos e serviços entregues na hora e quantidades certas, inteiramente de acordo com suas especificações e a menor custo possível é o que os clientes querem. É sob esse aspecto que o serviço logístico contribuirá para criar valor para os clientes a um custo aceitável para a empresa; portanto o serviço logístico é instrumento que pode ser usado para criar valor, pois está diretamente relacionado com o processo de entrega de produtos e serviços (Van Der Veeken, 1998).

Neste contexto de mercado extremamente competitivo e globalizado, o setor metalúrgico de bens de capital, especialmente o que produz máquinas e equipamentos, também enfrenta o desafio da retenção de clientes, mesmo dispondo de significativa representatividade econômica para o desenvolvimento do Brasil. Conforme dados da ABIMAQ (2001), no ano de 2000 o setor teve faturamento de R 21,08 bilhões e gerou 167 mil empregos diretos. A produção total das indústrias desse setor foi direcionada em 22,3\% para o mercado interno e 77,2\% para o mercado externo. As exportações foram destinadas: a) 36,8\% para os Estados Unidos e demais países do NAFTA (Acordo de Livre Comercio da América do Norte); b) 21,8\% para o MERCOSUL (Mercado Comum do Sul) e; c) $19,1 \%$ para a União Européia.

Com base nas justificativas acima resumidas, realizou-se uma pesquisa com o objetivo básico de se conhecer os fatores-chaves que ajudariam na retenção de clientes no setor industrial de produção de bens de capital, do ponto de vista deles. Este artigo é fundamentado no aprendizado obtido com a sua realização.

\section{Referencial Teórico}

\section{Retenção do Cliente}

Uma das definições clássicas de marketing diz que seu objetivo é ganhar e reter clientes. Na prática, o que se vê, é que a maior parte do esforço de marketing 
nas empresas está mais focado na obtenção do que na conservação dos clientes (Christopher, 1992). Segundo Reichheld (2000), a taxa de retenção de clientes tenderá a aumentar, sempre que a empresa criar valor para os três integrantes do sistema de negócios: clientes, empregados e investidores. Com o intuito de ressaltar a importância da retenção de clientes, Kotler (1999) afirma que custa cinco vezes mais conquistar um novo cliente do que manter o cliente atual satisfeito. Christopher (1999) também concorda que é mais lucrativo manter um cliente do que conseguir novo negócio, pois pode levar algum tempo até o novo cliente proporcionar lucro. Esse mesmo autor defende que, quanto mais satisfeito o cliente estiver com os serviços prestados, mais ele direciona suas compras para aquela empresa; e vender para esses clientes é mais fácil, os custos são mais baixos e clientes satisfeitos podem indicar a empresa para outros clientes.

Portanto reter clientes é mantê-los como compradores ativos, lucrativos e por um período de tempo satisfatório para a empresa.

Ao considerar os vários aspectos da retenção de clientes, Christopher (1999) cita que o serviço prestado a eles é fator fundamental para a sua conquista e retenção. Segundo aquele autor, o cliente de hoje, em quase todos os mercados, está exigindo níveis de desempenho de serviços mais elevados de seus fornecedores, sobretudo no que diz respeito à qualidade, entregas rápidas, flexibilidade e confiabilidade da entrega do produto. Embora várias empresas americanas tenham adotado a satisfação do cliente como seu indicador de desempenho mais importante, Day (1999) acha pouco eficaz medir a satisfação do cliente desta maneira, pois nem sempre os graus de satisfação se correlacionam com o comportamento subseqüente. Esse autor argumenta ainda que na maioria dos mercados, $60 \%$ a $80 \%$ dos clientes dissidentes disseram estar satisfeitos ou muito satisfeitos em uma última pesquisa antes de sua deserção.

Apesar dessa realidade, um número grande de empresas enfatizavam o critério da fidelidade. Os clientes fiéis não apenas compravam mais, como eram menos sensíveis aos preços; servi-los era menos dispendioso e não exigia os altos custos de encontrar e atrair novos clientes (Day, 1999).

Christopher (1992, p. 35) cita que uma medição simples da retenção do cliente pode ser feita com a seguinte pergunta: "quantos dos clientes que tínhamos 12 meses atrás ainda temos hoje?”. Rosa e Kamakura (2001) argumentam que as pesquisas de satisfação de clientes são os instrumentos comumente utilizados para mapear e mensurar a sua satisfação, embora haja a possibilidade da ocorrência do efeito Halo, que pode ser entendido como a situação em que as medidas de percepção são influenciadas pela avaliação geral, habilitando-se a distorção de interpretação das percepções específicas do cliente. Reichheld e 
Sasser (apud Day, 1999), descobriram que reduzindo em 5\% a deserção dos clientes, as empresas seriam capazes de aumentar os lucros em uma base de $25 \%$ a $85 \%$. Reichheld (2000) argumenta que para as empresas conseguirem a lealdade dos seus clientes é necessário considerar os seguintes fatores em sua estratégia: produto que agrega valor e o nível da qualidade dos serviços prestados.

A qualidade dos produtos é muito importante para a retenção de clientes; entretanto o destaque dado à qualidade dos serviços prestados está baseado na menção de Bowersox (2001, p. 77) de que diversos setores industriais já utilizam a logística como estratégia desenvolvida a partir do entendimento das expectativas do cliente, visando a conquistar a sua lealdade.

Assim, a partir da descoberta de que as empresas projetam e gerenciam sistemas que tem objetivos focalizados internamente, em vez de objetivos externos (Christopher, 1992) a estratégia de retenção de clientes deve ser desenvolvida a partir do mercado.

\section{Fatores-chaves para a Retenção de Clientes}

Um dos aspectos importantes para a retenção de clientes é a capacidade da empresa em medir o desempenho dos fatores ou atividades importantes para a sua retenção. Evidentemente que o interesse maior do administrador é a evolução ou o desempenho dos fatores medidos, cuja expectativa sobre os resultados influenciará a sua rotina de planejamento.

Para Tubino (1999) os principais fatores de desempenho podem ser colocados em quatro grupos: custo, qualidade, desempenho de entregas e flexibilidade. Slack (1993) considera cinco fatores principais de desempenho competitivo: qualidade, rapidez, confiabilidade, flexibilidade e custo. Para Davis et al. (2001) os fatores principais de desempenho competitivo são: produtividade, capacidade, qualidade, velocidade de entrega, flexibilidade e velocidade do processo.

Tracey (1998) complementa que o nível de flexibilidade de manufatura está relacionado com a eficiência logística, serviço ao cliente e desempenho das empresas.

O serviço ao cliente pode ser gerenciado, é atividade que pode ser mensurada com precisão, apresenta níveis de desempenho e pode ser vista como filosofia de gestão, o que ressalta a importância do marketing orientado para o cliente. Portanto o objetivo do serviço ao cliente, aliado à cadeia de suprimentos eficiente, é o fornecimento de benefícios significativos ao cliente (Lalonde Zinszer apud Bowersox, 2001, p. 70-71). 
Há um consenso de que para se melhorar o desempenho, de qualquer fatorchave, é indispensável que ele seja medido. É raro, contudo, que uma única medida seja usada para cada objetivo de desempenho, pois elas são compostas de muitas medidas menores. Usualmente utiliza-se um conjunto de medidas, cada uma com sua particular representação de objetivos de desempenho.

As prioridades de melhoramentos de desempenho são determinadas simultaneamente pela consideração da importância relativa de cada fator-chave de serviços atribuída e pelo desempenho de cada fator-chave das operações em relação à concorrência.

Para Christopher (1992), as organizações que enfatizam apenas fatores-chaves das operações, isto é, aqueles ligados às características do produto, enfrentarão forte desvantagem na competição com aquelas empresas que incrementam o produto básico com serviços de valor adicionado. Essa idéia pode ser reforçada no exemplo simples de que, em termos de características tangíveis, produto acabado no armazém é o mesmo que produto acabado nas mãos do cliente. Entretanto é claro que o produto nas mãos do cliente tem muito mais valor que o produto no armazém (Christopher, 1992, p. 17).

Portanto é primordial às empresas conhecerem os fatores que influenciam o comportamento dos compradores no contexto do serviço ao cliente, identificar quais os fatores-chaves que são vistos por ele como os mais importantes e, a partir daí, desenvolver processos de gerenciamentos logísticos, para que os objetivos dos serviços ao cliente sejam atingidos, garantindo, assim, a sua retenção (Christopher, 1992).

Para este estudo, assumiram-se como fatores-chaves de desempenho competitivo em serviços aqueles fatores ou atividades fundamentais para a retenção dos clientes, segundo o enfoque da vantagem competitiva baseada nas teorias de marketing e da administração da produção.

\section{Metodologia da Pesquisa: Objetivos, Amostra e Tratamento DOS DADOS}

\section{Objetivos}

O objetivo principal da pesquisa, objeto deste artigo, foi identificar, do ponto de vista do cliente, os fatores-chaves de serviços prestados pelas empresas industriais associadas à ABIMAQ que contribuem para sua retenção. 
Como objetivo específico, procurou-se identificar a importância que os clientes atribuíam àqueles fatores-chaves.

Deve-se destacar que o pressuposto básico do estudo foi o de que os fatores significativos e relevantes de retenção do cliente eram gerados pelos próprios clientes. Assim, uma vez definidos estes fatores, seria possível estabelecer a importância relativa de cada um deles e verificar o grau em que diferentes tipos de clientes estão preparados para barganhar em aspectos do serviço, conforme a capacidade do sistema logístico da empresa.

O método da pesquisa foi o descritivo, tendo-se adotado amostra não probabilística. Por isso as inferências extraídas da amostra devem ser ressalvadas, em função das limitações deste tipo de abordagem (Kerlinger, 1980).

\section{Amostra e Coleta dos Dados}

Inicialmente foi levantado o número de empresas do setor de máquinas e equipamentos associadas à ABIMAQ. Verificou-se que em todo país havia 1.209 empresas associadas, sendo que as principais estavam situadas nas regiões sul e sudeste do Brasil. Assim, dada a representatividade destas regiões, foram escolhidas, por conveniência, 210 empresas situadas nos Estados de São Paulo, Rio de Janeiro, Rio Grande do Sul, Paraná, Minas Gerais e Bahia, para a coleta dos dados. O instrumento utilizado foi o questionário composto de questões fechadas, enviados aos executivos da área de Suprimentos / Compras das empresas selecionadas. O levantamento ocorreu no último trimestre de 2001.

O questionário foi estruturado em três blocos.

- No primeiro bloco procurou-se levantar sucintamente o perfil dos respondentes e da empresa.

- O segundo bloco tratou dos fatores-chaves de retenção do cliente. A definição dos fatores-chaves foi feita com base nos conceitos dos principais fatores de desempenho competitivo emitidos pelos diversos autores mencionados no Referencial Teórico. Considerar as áreas de marketing e operações foi de fundamental importância, pois a qualidade do desempenho do serviço ao cliente depende principalmente da habilidade com que o sistema logístico é projetado e gerenciado; ou, colocado de maneira mais direta: o resultado de toda a atividade da logística é o serviço ao cliente. Assim, foram formuladas 10 assertivas, consideradas pelos autores deste artigo como as mais representativas. Essas assertivas foram colocadas em uma escala única de Discordância / 
Concordância, composta de seis pontos, de maneira que, quanto maior fosse o grau da escala assinalado, maior seria a concordância com a assertiva apresentada.

- O terceiro bloco foi destinado a levantar a ordem de importância, atribuída pelo entrevistado (cliente) às assertivas, devendo escolher apenas 4 delas.

É importante ressaltar que, no segundo bloco do questionário, foi solicitado ao respondente que manifestasse o seu grau de Discordância / Concordância em cada assertiva apresentada. No terceiro bloco do questionário foi solicitado ao respondente que escolhesse, por ordem de prioridade, as quatro assertivas mais importantes para a sua retenção, apresentadas no bloco anterior. Buscou-se, com isso, conhecer a intenção dele de voltar a comprar do mesmo fornecedor.

A adoção de duas diferentes formas de identificação dos fatores-chaves de desempenho para a retenção de clientes teve por finalidade verificar se as escolhas dos fatores-chaves independiam da metodologia utilizada.

\section{Tratamento dos Dados}

Para o tratamento dos dados foram utilizadas:

- a estatística descritiva para tratar das descrições dos dados coletados por meio de freqüências e porcentagens das respostas obtidas;

- a análise multivariada, na qual se aplicou-se a técnica da análise fatorial (Malhotra, 2001; Hair et al, 1998), com a finalidade de reduzir o número de variáveis e verificar a existência dos fatores importantes para a retenção de clientes.

\section{Análise dos Dados e Resultados}

\section{Caracterização das Respostas}

Dos 210 questionários enviados às empresas e direcionados aos executivos do Departamento de Suprimentos / Compras retornaram 38, representando 3,14\% da população ou 18,10\% das empresas escolhidas para a pesquisa. Essa amostra apresentou algumas características consideradas importantes para posterior análise dos resultados: (1) 47,8\% dos respondentes ocupavam o cargo de diretor ou gerente de compras e $52,2 \%$ ocupavam o cargo de supervisor de compras ou correlato; (2) 15,8\% das empresas pertenciam ao setor metalúrgico, 2,6\% ao 
siderúrgico, 13,2\% ao químico, 15,8\% ao petroquímico, 13,2\% ao de máquinas e equipamentos e $39,4 \%$ a outros setores como serviços e beneficiadores de metais não ferrosos; (3) 2,6\% das empresas tinham um faturamento anual de até R \$ 120 milhões, 15,8\% de R \$ 120 milhões a R \$ 1.200 milhões e 31\% acima de R 1.200 milhões.

\section{Grau de Importância dos Elementos de Retenção}

Utilizou-se a freqüência de ocorrência, para determinar a ordem de importância para os quatro fatores-chaves de retenção de clientes. Os resultados estão apresentados na Tabela 1.

\section{Tabela 1: Porcentagem de Respostas Atribuídas aos Fatores-Chaves de Retenção de Clientes}

\begin{tabular}{|c|l|c|c|c|c|}
\hline \multicolumn{2}{|l|}{ FATORES-CHAVES DE RETENÇÃO DO CLIENTE } & Primeiro & Segundo & Terceiro & Quarto \\
\hline 1 & Preço & 26,3 & 31,6 & 5,3 & 18,4 \\
\hline 2 & Assistência Técnica & 2,6 & 2,6 & 2,6 & 7,9 \\
\hline 3 & Sistema de Garantia da Qualidade & 15,8 & 13,2 & 5,3 & 0 \\
\hline 4 & Garantia dos Produtos & 7,9 & 13,2 & 13,2 & 10,5 \\
\hline 5 & Qualidade dos Produtos & 47,4 & 18,4 & 10,5 & 5,3 \\
\hline 6 & Informação sobre a Posição dos Pedidos & 0 & 0 & 0 & 5,3 \\
\hline 7 & Velocidade de Entrega & 0 & 2,6 & 18,4 & 7,9 \\
\hline 8 & Confiabilidade de Entrega & 0 & 15,8 & 26,3 & 18,4 \\
\hline 9 & Flexibilidade (Adaptação do processo ao cliente) & 0 & 2,6 & 7,9 & 21,1 \\
\hline 10 & Rastreabilidade dos Produtos & 0 & 0 & 10,5 & 5,2 \\
\hline
\end{tabular}

A Tabela 1 evidencia que o fator Qualidade dos Produtos foi o mais valorizado, com 47,4\% das respostas. O fator Preço aparece em segundo lugar com 31,6\%; Confiabilidade de Entrega e Flexibilidade apareceram em terceiro e quarto lugares com $26,3 \%$ e $21,1 \%$ respectivamente. O destaque deste resultado é o fator Qualidade dos Produtos, que aparece em primeiro lugar como fator de retenção do cliente e de forma bastante significativa, com $50 \%$ a mais de respostas do que o segundo fator Preço, que apareceu com 31,6\%.

\section{Fatores-Chaves para a Retenção do Cliente}

Os dados coletados por meio das 10 assertivas distribuídas pela escala de Discordância / Concordância, foram tratados mediante a aplicação da freqüência de ocorrência, para determinar os fatores-chaves mais importantes para a retenção do cliente, metodologia diferente da metodologia aplicada no item anterior (item 4.2). Na Tabela 2 estão apresentadas as freqüências das respostas obtidas. 
Tabela 2: Porcentagem de Respostas Atribuídas aos Atributos para a Retenção do Cliente

\begin{tabular}{|c|l|c|c|c|c|c|c|}
\hline \multicolumn{2}{|c|}{$\begin{array}{c}\text { FATORES-CHAVE DE RETENÇÃO DO } \\
\text { CLIENTE }\end{array}$} & \multicolumn{7}{c|}{ ESCALA } \\
\cline { 2 - 9 } & (DT) & (DM) & (DP) & (CP) & (CM) & (CT) \\
\hline 1 & Preço & 5,3 & 0 & 0 & 15,8 & 34,2 & 44,7 \\
\hline 2 & Assistência Técnica & 0 & 0 & 0 & 7,9 & 42,1 & 50,0 \\
\hline 3 & Sistema de Garantia da Qualidade & 0 & 0 & 2,6 & 26,3 & 31,6 & 39,5 \\
\hline 4 & Garantia dos Produtos & 0 & 0 & 0 & 5,3 & 28,9 & 65,8 \\
\hline 5 & Qualidade dos Produtos & 0 & 0 & 2,6 & 2,6 & 13,2 & 81,6 \\
\hline 6 & Informação sobre a Posição dos Pedidos & 0 & 0 & 0 & 7,9 & 52,6 & 39,5 \\
\hline 7 & Velocidade de Entrega & 0 & 0 & 0 & 13,2 & 36,8 & 50,0 \\
\hline 8 & Confiabilidade de Entrega & 0 & 2,6 & 0 & 0 & 28,9 & 68,4 \\
\hline 9 & Flexibilidade (adaptação ao processo do cliente) & 0 & 0 & 2,6 & 10,5 & 47,4 & 39,5 \\
\hline 10 & Rastreabilidade dos Produtos & 0 & 0 & 0 & 18,4 & 31,6 & 50,0 \\
\hline (DT) Discordo Totalmente & \multicolumn{7}{|c|}{ (CP) Concordo Pouco } \\
(DM) Discordo Muito & (CM) Concordo Muito \\
(DP) Discordo Pouco & (CT) Concordo Totalmente \\
\hline
\end{tabular}

Os resultados obtidos com o tratamento dos dados indicaram acentuada incidência de respostas no ponto de Concordância da escala para o fator Qualidade dos Produtos, com a maior freqüência (81,6\%), verificada no grau de importância da escala Concordo Totalmente. Seguem, por graus de importância, em segundo e terceiro lugares, as assertivas referentes aos fatores Confiabilidade de Entrega e Garantia dos Produtos respectivamente. Em quarto lugar aparecem com a mesma freqüência de 50,0\% as assertivas referentes aos fatores Assistência Técnica, Velocidade de Entrega e Rastreabilidade dos Produtos.

Observe-se que na Tabela 1, cujos dados foram coletados por ordem de importância, em que os respondentes priorizaram apenas quatro elementos de retenção ao cliente, verificou-se que o fator Qualidade dos Produtos foi o mais valorizado, com 47,4\% e seguido dos fatores Preço, Confiabilidade de Entrega e Flexibilidade, com 31,6\%, 26,3\% e 21,1\%, respectivamente.

Quando foi mudado o método de identificação dos fatores-chaves de retenção do cliente, conforme mostra os dados da Tabela 2, apenas o fator Qualidade dos Produtos confirmou-se como mais importante para a retenção do cliente.

Observe-se que a análise dos resultados apresentada na Tabela 2 se deu com grande número de variáveis ou fatores-chaves. Entretanto havia a possibilidade de inferir o mesmo resultado a partir da investigação de um conjunto menor de fatores-chaves, mediante sua identificação naquele conjunto de variáveis. Isso seria viável com a aplicação da técnica da análise fatorial que, segundo Hair et al (1998), é recomendada nos seguintes casos: (a) descobrir a 
estrutura de um conjunto de medições; (b) reduzir grande massa de dados da pesquisa em quantidade gerenciável; (c) auxiliar o pesquisador na construção de escalas, reagrupando as variáveis em fatores independentes e atribuindo um peso a cada variável para ser combinado na escala e; (d) identificar fatores não correlacionados.

Evidentemente, em algumas ocasiões, é possível intuir que várias medidas podem compor um fator (ou indicador). No entanto é preferível, ao invés de propor subjetivamente a criação de um indicador, submeter os dados da amostra a uma análise fatorial que aponte objetivamente essa agregação de medidas (Pereira, 1999), conforme será tratado a seguir.

\section{Análise Fatorial para os Elementos de Retenção do Cliente}

O primeiro passo para identificar as dimensões subjacentes das variáveis para reduzi-las a uma quantidade gerenciável e representativa da amostra, foi examinar o ajuste dos dados às premissas da análise fatorial. Como essa técnica trata de correlações entre as variáveis para derivar fatores, a matriz de correlações resultante está apresentada na Tabela 3.

\section{Tabela 3: Correlação Matricial entre os Fatores-chaves de Retenção do Cliente}

\begin{tabular}{|c|c|c|c|c|c|c|c|c|c|c|}
\hline $\begin{array}{l}\text { FATORES-CHAVE DE } \\
\text { RETENÇÃO DO CLIENTE }\end{array}$ & 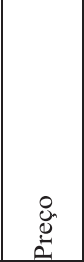 & 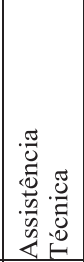 & 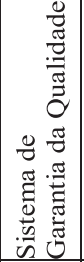 & 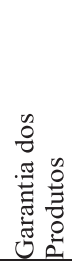 & 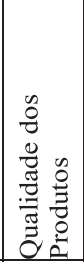 & 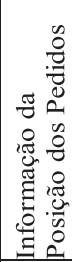 & 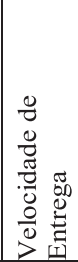 & 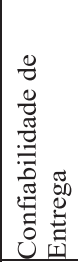 & 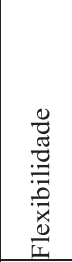 & 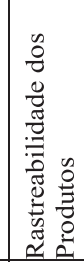 \\
\hline Preço & 1,000 & & & & & & & & & \\
\hline Assistência Técnica & $-0,01$ & 1,000 & & & & & & & & \\
\hline Sistema de Garantia da Qualidade & $\mid-0,28$ & 0,369 & 1,000 & & & & & & & \\
\hline Garantia dos Produtos & $-0,07$ & 0,305 & 0,422 & 1,000 & & & & & & \\
\hline Qualidade dos Produtos & 0,510 & 0,079 & $-0,11$ & $-0,07$ & 1,000 & & & & & \\
\hline Informação da Posição dos Pedidos & $-0,11$ & 0,200 & 0,052 & $-0,09$ & $-0,06$ & 1,000 & & & & \\
\hline Velocidade de Entrega & 0,090 & 0,006 & 0,167 & 0,097 & $-0,08$ & 0,463 & 1,000 & & & \\
\hline Confiabilidade de Entrega & 0,594 & $-0,15$ & $-0,36$ & 0,005 & 0,614 & $-0,02$ & $-0,02$ & 1,000 & & \\
\hline Flexibilidade & $\mid-0,32$ & 0,012 & 0,175 & 0,094 & $-0,15$ & 0,358 & 0,388 & $-0,12$ & 1,000 & \\
\hline Rastreabilidade dos Produtos & $-0,09$ & 0,269 & 0,437 & 0,278 & $-0,10$ & 0,406 & 0,370 & $-0,20$ & 0,472 & 1,000 \\
\hline
\end{tabular}

Determinante $=4,020 \mathrm{E}-02$

KMO (Kaiser-Meyer-Olkin), Measure of Sampling Adequacy (MSA): 0,56

BTS (Bartlett's Test of Sphericity) Approx. Chi-Square: 105,5202

Graus de Liberdade (degree of freedom): 45; Nível de Significância: 0,000000907 
Por essa Tabela pode-se verificar que os maiores coeficientes de correlação, ou padrões similares de fatores, estão nas intersecções da Qualidade dos Produtos com o Preço, da Confiabilidade de Entrega com o Preço e da Confiabilidade de Entrega com a Qualidade dos Produtos, assumindo os valores 0,510; 0,594 e 0,614 respectivamente. $\mathrm{O}$ ajuste dos dados às premissas da análise fatorial dada por um valor de Measure of Sampling Adequacy (MSA) menor do que 0,60 é considerado uma adequação aos dados mediocre, e valor menor do que 0,50 é inaceitável (Hair et al, 1998).

A Tabela 3 mostra que o valor de MSA obtido é igual a 0,56, indicando que os dados têm adequação imprópria para a análise fatorial, tentando aproximar-se da adequação medíocre. No entanto a hipótese de que as correlações entre as variáveis possam ser zero pode ser descartada, pois o nível de significância e o BTS da amostra são significativos e indicam a existência das correlações. Para prosseguir na análise, dada a aparente inadequação dos dados à análise fatorial, foi gerada a matriz anti-imagem de correlação, que é matriz de correlações parciais (correlação de uma variável contra a outra, controlados os efeitos de todas as outras consideradas no modelo).

Nessa matriz, a diagonal mede a adequação amostral para cada variável e o julgamento faz-se pelos mesmos valores críticos utilizados para o teste KMO / MSA. A Tabela 4, apresenta a matriz de correlações parciais obtida.

\section{Tabela 4: Matriz de Correlações Parciais dos Fatores-chaves (Matriz Anti-imagem)}

\begin{tabular}{|c|c|c|c|c|c|c|c|c|c|c|}
\hline $\begin{array}{l}\text { FATORES-CHAVE DE } \\
\text { RETENÇÃO DO CLIENTE }\end{array}$ & $\begin{array}{l}8 \\
0 \\
0\end{array}$ & 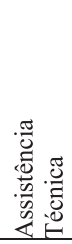 & 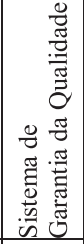 & 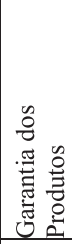 & 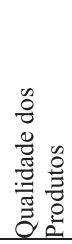 & 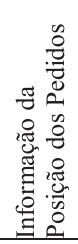 & 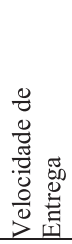 & 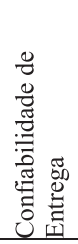 & 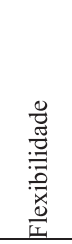 & 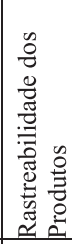 \\
\hline Preço & 0,532 & & & & & & & & & \\
\hline Assistência Técnica & $-0,16$ & 0,487 & & & & & & & & \\
\hline Sistema de Garantia da Qualidade & 0,218 & $-0,20$ & 0,662 & & & & & & & \\
\hline Garantia dos Produtos & 0,122 & $-0,29$ & $-0,29$ & 0,450 & & & & & & \\
\hline Qualidade dos Produtos & $-0,20$ & $-0,19$ & $-0,20$ & 0,208 & 0,624 & & & & & \\
\hline Informação da Posição dos Pedidos & 0,260 & $-0,32$ & 0,148 & 0,299 & 0,056 & 0,484 & & & & \\
\hline Velocidade de Entrega & $-0,36$ & 0,208 & $-0,17$ & $-0,13$ & 0,088 & $-0,42$ & 0,525 & & & \\
\hline Confiabilidade de Entre & $-0,42$ & 0,243 & 0,222 & $-0,33$ & $-0,50$ & $-0,22$ & 0,114 & 0,552 & & \\
\hline Flexibilidade & 0,400 & 0,046 & 0,084 & 0,030 & $-0,03$ & $-0,02$ & $-0,30$ & $-0,16$ & 0,609 & \\
\hline Rastreabilidade dos Produtos & $-0,26$ & $-0,02$ & $-0,30$ & $-0,19$ & 0,01 & $-0,32$ & 0,006 & 0,184 & $-0,39$ & 0,660 \\
\hline
\end{tabular}

Os valores mostrados na Tabela 4 apontam três fatores com valores abaixo de 0,50 Assistência Técnica, Garantia dos Produtos e Informação da Posição dos 
Pedidos. Como o fator Garantia dos Produtos tem o menor valor $(0,450)$, ele foi omitido para se obter novo conjunto de fatores com nível mínimo aceitável de adequação dos dados para a análise fatorial.

Na seqüência do tratamento dos dados, ao se retirar o fator-chave de retenção do cliente, Garantia dos Produtos, obteve-se nova matriz de correlação, apresentada na Tabela 5.

\section{Tabela 5: Correlação Matricial entre os Fatores-chave de Retenção do Cliente}

\begin{tabular}{|c|c|c|c|c|c|c|c|c|c|}
\hline $\begin{array}{l}\text { FATORES-CHAVES DE } \\
\text { RETENÇÃO DO CLIENTE }\end{array}$ & 递 & 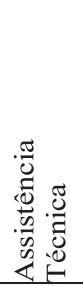 & 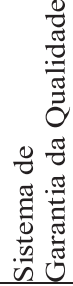 & 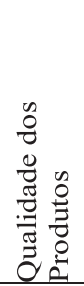 & 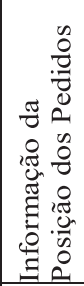 & 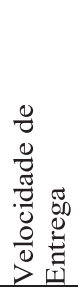 & 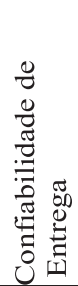 & $\begin{array}{l}\frac{0}{0} \\
\frac{\pi}{0} \\
: 0 \\
\overline{7} \\
\frac{0}{x} \\
\frac{0}{I}\end{array}$ & 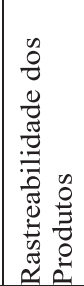 \\
\hline Preço & 1,000 & & & & & & & & \\
\hline Assistência Técnica & $-0,01$ & 1,000 & & & & & & & \\
\hline Sistema de Garantia da Qualidade & $-0,28$ & 0,369 & 1,000 & & & & & & \\
\hline Qualidade dos Produtos & 0,510 & 0,079 & $-0,11$ & 1,000 & & & & & \\
\hline Informação da Posição dos Pedidos & $-0,11$ & 0,200 & 0,052 & $-0,06$ & 1,000 & & & & \\
\hline Velocidade de Entrega & 0,090 & 0,006 & 0,167 & $-0,08$ & 0,463 & 1,000 & & & \\
\hline Confiabilidade de Entrega & 0,594 & $-0,15$ & $-0,36$ & 0,614 & $-0,02$ & $-0,02$ & 1,000 & & \\
\hline Flexibilidade & $-0,32$ & 0,012 & 0,175 & $-0,15$ & 0,358 & 0,388 & $-0,12$ & 1,000 & \\
\hline Rastreabilidade dos Produtos & $-0,09$ & 0,269 & 0,437 & $-0,10$ & 0,406 & 0,370 & $-0,20$ & 0,472 & 1,000 \\
\hline
\end{tabular}

Determinante $=6,123 \mathrm{E}-02$

KMO (Kaiser-Meyer-Olkin) Measure of Sampling Adequacy (MSA): 0,59

BTS (Bartlett's Test of Sphericity) Approx. Chi-Square: 92,63847

Graus de Liberdade (degree of freedom): 36; Nível de Significância: 0,000000694

Esse procedimento mostrou que a retirada da análise do fator Garantia do Produto não foi suficiente para adequar os dados à aplicação da análise fatorial, porquanto, embora o KMO / MSA tenha aumentado para 0,59, ainda é valor medíocre. Retornando-se à Matriz Anti-imagem, na Tabela 4, observa-se que o fator-chave de retenção do cliente Informação da Posição do Pedido, com valor de 0,484, é a próxima variável a ser retirada da análise. Assim, processando-se a análise fatorial sem os dois fatores, Garantia dos Produtos (já retirado no passo anterior) e Informação da Posição dos Pedidos, obteve-se a nova matriz de correlação, conforme está apresentada na Tabela 6. 


\section{Tabela 6: Correlação Matricial entre os Fatores-chaves de Retenção do Cliente}

\begin{tabular}{|c|c|c|c|c|c|c|c|c|}
\hline $\begin{array}{l}\text { FATORES-CHAVES DE } \\
\text { RETENÇÃO DO CLIENTE }\end{array}$ & 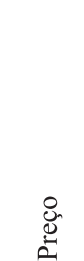 & 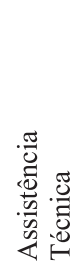 & 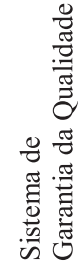 & 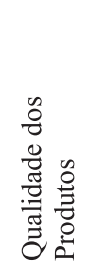 & 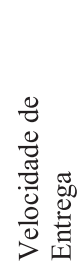 & 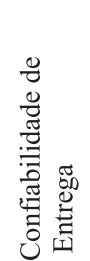 & $\begin{array}{l}\frac{0}{\tilde{a}} \\
\frac{\pi}{0} \\
\overline{0} \\
\frac{0}{x} \\
\frac{0}{I}\end{array}$ & 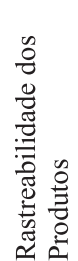 \\
\hline Preço & 1,000 & & & & & & & \\
\hline Assistência Técnica & $-0,009$ & 1,000 & & & & & & \\
\hline Sistema de Garantia da Qualidade & $-0,283$ & 0,369 & 1,000 & & & & & \\
\hline Qualidade dos Produtos & 0,510 & 0,079 & $-0,105$ & 1,000 & & & & \\
\hline Velocidade de Entrega & 0,090 & 0,006 & 0,167 & $-0,077$ & 1,000 & & & \\
\hline Confiabilidade de Entrega & 0,594 & $-0,150$ & $-0,358$ & 0,614 & $-0,024$ & 1,000 & & \\
\hline Flexibilidade & $-0,317$ & 0,012 & 0,175 & $-0,147$ & 0,388 & $-0,117$ & 1,000 & \\
\hline Rastreabilidade dos Produtos & $-0,085$ & 0,269 & 0,437 & $-0,100$ & 0,370 & $-0,197$ & 0,472 & 1,000 \\
\hline
\end{tabular}

Determinante $=9,919 \mathrm{E}-02$

KMO (Kaiser-Meyer-Olkin) Measure of Sampling Adequacy (MSA): 0,62

BTS (Bartlett's Test of Sphericity) Approx. Chi-Square: 77,41037

Graus de Liberdade (degree of freedom): 28; Nível de Significância: 0,00000161

O novo resultado, $\mathrm{KMO} / \mathrm{MSA}=0,62$ mostrado na Tabela 6, sugere existir, uma adequação medíocre dos dados à análise fatorial. Assim, prosseguiu-se o tratamento dos dados, assumindo-se, desde então, que as informações obtidas padeceriam de restrições quando fossem realizadas inferências a partir delas.

O passo seguinte foi a extração dos fatores Garantia dos Produtos e Informação da Posição dos Pedidos, da matriz de correlações, com a intenção de encontrar um conjunto de fatores que formassem uma combinação linear das variáveis da matriz de correlação. Dessa forma, se os fatores fossem altamente correlacionados entre si, eles seriam combinados para formar um fator, e assim sucessivamente com as demais variáveis da matriz de correlação. Na Tabela 7, têm-se a extração dos componentes principais, constituídos de oito fatores-chave que correspondem às variáveis originais.

\section{Tabela 7: Extração dos Componentes Principais}

\begin{tabular}{cl|c|c|c}
\hline Fatores-chave de Retenção do cliente & Eingenvalue & (\%) of variance & Cumulative (\%) \\
\hline 1 & Preço & 2,661 & 33,262 & 33,262 \\
2 & Assistência Técnica & 1,695 & 21,190 & 54,452 \\
3 & Sistema de Garantia da Qualidade & 1,262 & 15,779 & 70,231 \\
5 & Qualidade dos Produtos & 0,725 & 9,066 & 79,297 \\
7 & Velocidade de Entrega & 0,578 & 7,222 & 86,519 \\
8 & Confiabilidade de Entrega & 0,498 & 6,221 & 92,740 \\
9 & Flexibilidade & 0,319 & 3,986 & 96,726 \\
10 & Rastreabilidade dos Produtos & 0,262 & 3,274 & 100,000 \\
\hline
\end{tabular}


Com a aplicação da técnica da análise fatorial pelo critério varimax with kaizer normalization (Hair et al., 1998), obtiveram-se os componentes preponderantes, ou seja, aqueles com maior carga, como é apresentada na Tabela 8.

\section{Tabela 8: Fator de Carga (com Rotação - Varimax with Kaiser Normalization)}

\begin{tabular}{|c|c|c|c|c|c|}
\hline \multicolumn{2}{|c|}{ Fatores-chave de Retenção do Cliente } & Fator 1 & Fator 2 & Fator 3 & Communality \\
\hline 1 & Preço & 0,841 & $-0,050$ & $-0,071$ & 0,715 \\
\hline 2 & Assistência Técnica & 0,073 & $-0,070$ & 0,850 & 0,734 \\
\hline 3 & Sistema de Garantia da Qualidade & $-0,258$ & 0,222 & 0,743 & 0,667 \\
\hline 5 & Qualidade dos Produtos & 0,829 & $-0,095$ & 0,117 & 0,709 \\
\hline 7 & Velocidade de Entrega & 0,088 & 0,797 & $-0,008$ & 0,643 \\
\hline 8 & Confiabilidade de Entrega & 0,838 & $-0,010$ & $-0,269$ & 0,775 \\
\hline 9 & Flexibilidade & $-0,214$ & 0,793 & $-0,007$ & 0,675 \\
\hline 10 & Rastreabilidade dos Produtos & $-0,067$ & 0,681 & 0,481 & 0,700 \\
\hline \multicolumn{2}{|r|}{ Eingevalues } & 2,661 & 1,695 & 1,262 & \\
\hline \multicolumn{2}{|r|}{$(\%)$ of Variance } & 33,262 & 21,190 & 15,779 & \\
\hline
\end{tabular}

Com isso, foram identificados três componentes significativos para os fatoreschaves de retenção do cliente, referentes aos valores de eigenvalues maiores do que 1, representativos de $70,231 \%$ da variância do conjunto de dados originais, identificados na tabela das cargas fatoriais da matriz rodada. $\mathrm{O}$ primeiro fator englobou três variáveis originais, as de números 1,5 , e 8 , aqui denominado subjetivamente de Fator Principal. A análise desses dados evidenciou que eles estavam diretamente relacionados aos aspectos principais, quando um cliente realiza a compra.

Assim, assumiu-se que esse fator estava relacionado com o aspecto emocional ou da consciência intuitiva do cliente. O segundo fator foi explicado por três variáveis, as de números 7, 9 e 10, aqui denominado de Fator Secundário. O terceiro fator, aqui denominado de Fator Interno, foi evidenciado por duas variáveis originais, as de números 2 e 3, integrantes do Sistema de Gestão da Qualidade. Os fatores, Garantia dos Produtos e Informações da Posição dos Pedidos revelaram-se como elementos isolados ou independentes; isso se deveu à baixa interatividade com os outros elementos, como foi mostrado na Tabela 4. Como conseqüência, os dez fatores de retenção foram reduzidos para apenas cinco: Fator Principal, Fator Secundário, Fator Interno, Garantia dos Produtos e Informações da Posição dos Pedidos.

No Quadro 1, estão apresentados os resultados da análise fatorial efetuada para esses fatores-chaves de retenção do cliente, onde se destacaram os componentes principais, caracterizadores dos fatores extraídos. 


\section{Quadro 1: Fatores Determinantes Relacionados aos Elementos de Retenção do Cliente}

\begin{tabular}{|c|c|l|c|}
\hline $\begin{array}{c}\text { Ordem } \\
\text { do fator }\end{array}$ & Denominação & \multicolumn{1}{|c|}{$\begin{array}{c}\text { Variáveis determinantes } \\
\text { (Fatores-chaves) }\end{array}$} & $\begin{array}{c}\text { Alpha ( } \\
\text { Cronbach }\end{array}$ \\
\hline 1 & $\begin{array}{c}\text { Fator Principal } \\
\text { (abrangentes) }\end{array}$ & $\begin{array}{l}\text { Preço } \\
\text { Qualidade dos Produtos } \\
\text { Confiabilidade de Entrega }\end{array}$ & 0,7534 \\
\hline 2 & Fator Secundário & $\begin{array}{l}\text { Velocidade de Entrega } \\
\text { Flexibilidade } \\
\text { Rastreabilidade dos Produtos }\end{array}$ & 0,6763 \\
\hline 3 & $\begin{array}{c}\text { Fator Interno } \\
\text { (área) }\end{array}$ & $\begin{array}{l}\text { Assistência Técnica } \\
\text { Sistema de Garantia da Qualidade }\end{array}$ & 0,5201 \\
\hline 4 & & Garantia dos Produtos & \\
\hline 5 & & Informações da Posição dos Pedidos & \\
\hline
\end{tabular}

No Quadro 1, observa-se que o Fator Principal, o Fator Secundário e o Fator Interno têm consistência ou confiabilidade interna, dado pelo Alpha $(\propto)$ de Chronbach, de 0,7534, 0,6763 e 0,5201 respectivamente. Os fatores Garantia dos Produtos e Informação da Posição dos Pedidos têm baixa correlação com os demais fatores, como foi verificado na Tabela 4. Assim, os 10 fatores-chaves de retenção do cliente podem ser resumidos em cinco: Fator Principal, Fator Secundário, Fator Interno, Garantia dos Produtos e Informações da Posição dos Pedidos. O Fator Principal e o Fator Secundário, sozinhos, explicam quase 55\% da variância e seus componentes têm coerência ou similaridade quanto ao seu agrupamento. Os demais Fatores representam o restante das variâncias explicadas.

Por outro lado, o intervalo de valores possíveis para o Apha ( $\propto$ ) de Chronbach é entre 0 e 1 , cujo julgamento da combinação dos fatores-chaves resultantes dos valores obtidos, se é satisfatório ou não, cabe exclusivamente ao pesquisador, pois não há ponto de corte ideal que se possa arbitrar para a concepção de qualquer indicador (Pereira, 1999). Assim sendo, pode-se dizer que os 10 fatoreschaves de retenção podem ser resumidos em apenas dois: Fator Principal e Fator Secundário, porque além de representar quase 55\% da variância, possuem em sua composição os principais fatores-chaves de retenção do cliente, segundo os autores que se dedicam a esse campo de conhecimento e à pesquisa realizada.

\section{Conclusões e Sugestões}

Voltando-se ao objetivo principal do estudo, a amostra de empresas associadas à ABIMAQ, segundo o ponto de vista dos clientes, revelou que o fator-chave 
para a retenção é a Qualidade dos Produtos. Esse resultado prevaleceu, nos dois procedimentos utilizados para identificar o fator-chave para a retenção dos clientes, conforme resumido a seguir.

a) A manifestação dos respondentes, diante de uma escala graduada de Discordância / Concordância, mostrou em primeiro lugar o fator-chave Qualidade dos Produtos, seguido de Confiabilidade de Entrega e Garantia dos Produtos em segundo e terceiro lugar, respectivamente. Em quarto lugar apareceram os fatores-chaves Assistência Técnica, Velocidade de Entrega e Rastreabilidade dos Produtos.

b) Quando solicitados a escolher, dentre as assertivas enunciadas, quatro delas por ordem de importância, o fator-chave revelado em primeiro lugar também foi a Qualidade dos Produtos, seguido de Preço, Confiabilidade de Entrega e Flexibilidade em segundo, terceiro e quarto lugares, respectivamente.

Com relação ao objetivo específico, verificou-se o que segue:

a) Somente a Qualidade dos Produtos pode ser considerada como o principal fator-chave para a retenção do cliente, nessa amostra estudada, uma vez que houve coincidência quanto às diferentes técnicas utilizadas.

b) Com a finalidade de reduzir os 10 fatores-chaves em um número menor de variáveis para facilitar o seu gerenciamento, com a aplicação da técnica da análise fatorial, chegou-se a apenas dois fatores ou componentes principais denominados por Fator Principal e Fator Secundário. Esses dois fatores, sozinhos, explicam quase $55 \%$ da variância, mantendo certa familiaridade entre os seus componentes. Observe-se que estes Fatores têm certa coerência ou similaridade quanto ao seu agrupamento. Os demais Fatores representam o restante das variâncias explicadas.

c) O Sistema de Garantia da Qualidade, conforme Quadro 1, foi denominado fator interno. Pode ser considerado importante para a empresa manter-se competindo no mercado; entretanto não se mostrou como fator relevante para a retenção de clientes. Esta conclusão permite inferir que os processos logísticos, por serem atividades que acontecem antes, durante e após os processos de fabricação, permitindo à empresa desenvolver habilidades para satisfazer os clientes (Tracey, 1998), tornam as ações internas da empresa visíveis aos clientes, favorecendo a sua retenção.

Este estudo mostrou que não constitui uma das tarefas mais fáceis identificar os fatores-chaves de retenção do cliente, conforme já constataram Day (1999), Christopher (1992), Rosa e Kamakura (2001) e outros. Entretanto todos os autores 
que trabalham nesse campo de conhecimento são unânimes quanto à sua importância para conectar o mercado à rede de distribuição, ao processo de fabricação e às atividades de aquisição, de tal modo que os clientes recebam níveis cada vez mais altos de serviços, ainda assim mantendo os custos baixos. Ressalve-se, porém, que este estudo não permite fazer inferências para universos mais amplos, dadas as limitações da amostra não ser probabilística e ter atingido um número restrito de empresas.

De qualquer maneira, os resultados obtidos ensejam algumas sugestões, mesmo que de caráter restrito à amostra estudada.

1) Evidencia-se que os executivos das empresas associadas à ABIMAQ privilegiam o produto em suas demandas, pois que ter como fatorchave Qualidade dos Produtos como principal fator de retenção é uma condição sine qua non. Segundo Slack (1993) é fundamental ampliar esse enfoque, isto é, garantir um mínimo de qualidade aceitável mas incluir no seu processo de negócios outros fatores-chaves como a confiabilidade, velocidade e a flexibilidade, pelo seu efeito no restante da cadeia interna.

2) A influência de um responsável por compras dentro de uma empresa não deve ser apenas pontual; deve ser muito maior. Ele precisa combinar as necessidades de mercado com a capacidade produtiva da empresa e satisfazer às necessidades de serviços ao cliente a um custo mínimo. Deve ainda, atentar para o fato de que as expectativas dos clientes, ao longo do tempo, são mutáveis.

À vista do exposto, sugere-se o prosseguimento desta pesquisa com a finalidade de: (1) Identificar nas empresas fornecedoras para o grupo da ABIMAQ se o processo logístico também é voltado para a Qualidade dos Produtos, conforme foi detectado por este estudo. (2) Verificar se as empresas fornecedoras que realizam o processo logístico voltado para a Qualidade dos Produtos têm a capacidade de reter mais clientes que as demais. Para tanto, pode-se utilizar a definição dada por Christopher (1992) citada no item 2.1 deste artigo. (3) Ampliar a amostra e desenvolver estudos comparativos entre os diversos setores da economia, as diferentes origens do capital (nacional e estrangeiro) ou mesmo diferentes regiões geográficas, para identificar os fatores-chaves de retenção do cliente de forma mais ampla e profunda. 
ReferênCIAs Bibliográficas

ABIMAQ.

Associação Brasileira da Indústria de Máquinas e Equipamentos.[S.l.], 2001.

BOWERSOX, D. J.;

CLOSS, D. J.

Logística empresarial: o processo de integração da cadeia de suprimento. São Paulo: Atlas, 2001.

CHRISTOPHER, M.

O marketing da logística. São Paulo: Futura, 1999.

Logística e gerenciamento da cadeia de suprimentos. São Paulo: Pioneira, 1992.

COHEN, D.

A nova ordem. Exame, São Paulo, Editora Abril, 1999.

DAVIS, M. M.;

AQUILANO, N. J.;

CHASE, R. B.

Fundamentos da administração da produção. Porto Alegre: Bookman, 2001.

DAY, G. S.;

REIBSTEIN, D. J.

A dinâmica da estratégia competitiva. Rio de Janeiro: Campus, 1999.
HAIR, J. F. et al.

Multivariate data analysis. 5e.ed. Englewood Cliffs, NJ: Prentice Hall, 1998.

HAMEL, G.;

PRAHALAD, C. K.

Competindo pelo futuro. 9.ed. Rio de Janeiro: Campus, 1995.

KERLINGER, F. N.

A metodologia da pesquisa em ciências sociais: um tratamento conceitual. São Paulo: EPU, 1980.

KOTLER, P.

Marketing para o século XXI: como criar, conquistar e dominar mercados. São Paulo: Futura, 1999.

MALHOTRA, N. K.

Pesquisa de marketing, uma orientação aplicada. Porto Alegre: Bookman, 2001.

PEREIRA, J. C. R.

Análise de dados qualitativos. 3-.ed. São Paulo: EDUSP, 1999.

REICHHELD, F.

O valor da fidelidade. HSM Management, ano 4, n. 21, jul./ ago. 2000. 
ROSA, F.;

KAMAKURA, W. A.

Pesquisas de satisfação de clientes e efeito halo: interpretações equivocadas? In: ENCONTRO ANUAL DA ANPAD, 25., 2001, Campinas. Anais... Rio de Janeiro: ANPAD, 2001. 1 CDROM.

SLACK, N.

Vantagem competitiva em manufatura. São Paulo: Atlas, 1993.

SLACK, N. et al.

Administração da produção. São Paulo: Atlas, 1997.
TRACEY, M.

The importance of logistics efficiency to customer service and firm performance. International Journal of Logistics Management, v. 9, n. 2, 1998.

TUBINO, D. F.

Sistemas de produção: a produtividade no chão de fábrica. Porto Alegre: Bookman, 1999.

VAN DER VEEKEN, D. J. M.; RUTTEN, W. G. M.

Logistics service management: opportunities for differentiation. International Journal of Logistics Management, v. 9, n. 2, 1998. 